Daimon. Revista Internacional de Filosofía, Suplemento no 8 (2020), pp. 5-19

ISSN: 1130-0507 (papel) y 1989-4651 (electrónico)

http://dx.doi.org/10.6018/daimon.406641

\title{
Presentación. \\ Ortega y el exilio, una relación frustrada pero fecunda
}

\author{
Presentation. \\ Ortega and exile, a frustrated but fruitful relationship
}

ANTOLÍN SÁNCHEZ CUERVO*

\begin{abstract}
Resumen: El presente suplemento ofrece una cartografía elemental del legado filosófico de Ortega y Gasset en el exilio republicano español de 1939. A lo largo de once contribuciones, se exploran los que podrían ser sus cuatro núcleos principales: el presunto exilio del propio Ortega o su relación problemática con el mismo; las dos grandes referencias de su proyección en el exilio, a saber, María Zambrano y José Gaos; otras dos referencias, de gran importancia aunque aún no lo suficientemente exploradas y cuya relación con el mundo del exilio fue además tardía, como las de Antonio Rodríguez Huéscar y Manuel Granell; la presencia de Ortega en otros autores del exilio, en un sentido más difuso y de formas menos explícita o focalizada en aspectos específicos, como fuera el caso de García Bacca, Ferrater Mora y Francisco Ayala

Palabras clave: Ortega y Gasset, exilio republicano, legado, filosofía española
\end{abstract}

\begin{abstract}
This special issue presents an elementary cartography of the philosophical legacy of Ortega y Gasset in the 1939 Spanish republican exile. Throughout eleven articles, the main topics are explored, in particular: the supposed exile oh Ortega himself or his problematic relationship with it; the two main references of his legacy in the 1939 Spanish exile, namely María Zambrano and José Gaos; two other references, of great importance but not yet sufficiently explored and whose relationship with exile was also late, such as Antonio Rodríguez Huéscar and Manuel Granell; Ortega's presence in other authors of exile in a more diffuse and less explicit sense or focused on specific aspects, such as the case of García Bacca, Ferrater Mora and Francisco Ayala

Keywords: Ortega y Gasset, republican exile, legacy, Spanish philosophy
\end{abstract}

Del 12 al 14 de marzo de 2018 tuvo lugar en la Fundación Ortega Marañón y en el Instituto de Filosofía del CSIC el Congreso Internacional El legado de Ortega y Gasset en el exilio republicano de 1939: continuidades y rupturas, dirigido por Antolín Sánchez Cuervo y Javier Zamora Bonilla en el marco de diversos proyectos de investigación ${ }^{1}$ y

* Científico Titular del Instituto de Filosofía del CSIC, en donde forma parte del grupo de investigación Filosofía social y política. Es Investigador Principal del proyecto El legado filosófico del exilio español de 1939: razón crítica, identidad y memoria (FFI2016-77009-R) y autor de más de un centenar de publicaciones sobre filosofía iberoamericana, especialmente sobre el exilio intelectual republicano de 1939.

1 "Redes intelectuales en Europa y América a través de los epistolarios de José Ortega y Gasset" (FFI2016-76891; "Redes intelectuales y políticas: la tradición liberal en torno a José Ortega y Gasset" (FFI2016-76891-C2-2-P); "El legado filosófico del exilio español de 1939: razón crítica, identidad y memoria” (FFI2016-77009-R) 
con la participación de reconocidos especialistas en el tema. A lo largo de tres jornadas, se impartieron conferencias y se celebraron diversas mesas redondas en las que se debatió en torno al que seguramente sea uno de los legados más amplios y heterogéneos del pensamiento de lengua española del siglo $\mathrm{XX}^{2}$. Siguiendo la senda del exilio republicano del 39, se dio buena cuenta de la dificultad que este legado ofrece cuando se quiere transitar por él más allá de unos cuantos lugares comunes; una dificultad que viene de lejos y que seguramente refleja la posición del propio Ortega en la España del primer tercio del siglo $\mathrm{XX}$, sobre todo en los años treinta, por su perfil un tanto ambiguo: Ortega, el promotor de la República que en cuestión de semanas se convierte en antirrepublicano; el liberal con veleidades, no ya conservadoras, sino abiertamente autoritarias; el crítico del totalitarismo que, en plena Guerra Civil española y en vísperas de la Segunda Guerra Mundial se permite coquetear con él ${ }^{3}$; el europeísta convencido que quiere salvar la circunstancia española a base de nacionalismo ${ }^{4}$; el filósofo de gran proyección en el mundo hispano-parlante que sin embargo nunca llegó a adentrarse en la América profunda. Ortega, el exiliado que en realidad nunca llegó a serlo del todo y que, cuando regresó a la España de Franco, tampoco lo hizo del todo...

Ortega había ido sembrando de ambigüedades y dificultades su propio futuro, el cual no será fácil de trasmitir. Ortega después de Ortega será el nombre de recepciones y recreaciones muy diversas, condicionadas además por la ruptura entre la España del interior y la del exilio -sin obviar las zonas grises entre una y otra. En todo caso, si la continuidad de Ortega en el horizonte específico del exilio es obvia por el radio de su magisterio antes de la guerra, no lo es menos la renuencia que proyectó en él, dada su hostilidad creciente hacia la legitimidad republicana, consumada primero en los años de la guerra, después en el regreso a la España de Franco tras la amarga experiencia de su estancia en Buenos Aires y tres años de residencia en Lisboa. Los jóvenes orteguianos o intelectuales que habían recibido alguna influencia de Ortega no podrían evitar cierta tensión entre la continuidad y la ruptura, lo cual habría de concretarse en recepciones de muy diverso perfil.

En relación con la continuidad, debe apuntarse que, en términos generales y en buena medida, el legado orteguiano sobrevivió al olvido gracias a la memoria del mismo que algunos de sus discípulos -directos o indirectos, en sentido amplio o estricto- activaron en el contexto del exilio. Una memoria que, si bien no podría igualar el contacto directo de los discípulos que se habían quedado en el interior, fluía libre de censuras, o bajo la que cada autor quisiera imponerse a sí mismo en función de sus estrategias de acomodo en las no siempre estables redes editoriales e intelectuales del exilio ${ }^{5}$. Y una memoria que, sobre todo, dotaba al legado orteguiano de una mayor proyección internacional, por

2 Véase la reseña de Cortés (2018).

3 Me refiero, obviamente, a su texto "En torno al pacifismo" incluido en la edición de 1938 de La rebelión de las masas, Ortega $(2013,411)$

4 Pienso en el protagonismo de Ortega en la fundación en 1932 del Frente Español, un partido político de perfil proto-fascista, que congregó a varios discípulos de Ortega en la estela de su creciente desafecto por la República y por el parlamentarismo.

5 ¿Para quién escribimos? se preguntaba, precisamente, un antiguo discípulo de Ortega como Francisco Ayala (1949). Ciertamente, no debemos idealizar la desinhibición o libertad de expresión del exiliado, ya que la búsqueda del receptor en una circunstancia compleja y de exclusión como la suya condiciona sin duda la forma y el contenido de la propia escritura. 
razones obvias y sin infravalorar por ello las estancias de Ortega como conferenciante en Estados Unidos, Alemania y Suiza en la última etapa de su vida. No es necesario caer en ningún estereotipo reduccionista que haga de la España del interior un páramo intelectual y exagere la obra cultural del exilio para reconocer que esta última tuvo un mayor peso y se caracterizó por una mayor complejidad, por sus cifras, sus aportaciones y su diseminación geográfica. En el exilio, la impronta de Ortega quedará solapada, no ya con otras influencias, sino también con las discusiones y los debates de centros académicos muy diversos, dotados de condiciones institucionales desiguales pero mucho más proclives a la circulación del saber, que aquellos otros inhibidos bajo la disciplina de un régimen entre fascista y clerical, con todos los huecos, resquicios y meritorios contrapuntos que se quieran salvar y dignificar.

Está aún por hacer una cartografía transnacional del pensamiento del exilio en general y del legado orteguiano en particular, que nos permita identificar sus principales núcleos, redes y constelaciones de referencias. Por lo pronto, cabría trazar una primera aproximación en función de autores, obras y contextos concretos, y ése es, precisamente, el objeto de las páginas siguientes. En ellas se intenta ofrecer una cartografía elemental del orteguismo del exilio republicano que dé cuenta de sus nombres, conceptos y contextos fundamentales, en base a la que puedan articularse en el futuro otras aproximaciones mucho más ambiciosas. A lo largo de once contribuciones, se exploran los que podrían ser los cuatro núcleos principales de este monográfico: el presunto exilio del propio Ortega o su problemática relación con el mismo, con todo lo que ellos implica; las dos grandes referencias de su proyección filosófica en el exilio o al menos las más conocidas, a saber, María Zambrano y José Gaos; otras dos referencias, de gran importancia aunque aún no lo suficientemente exploradas y cuya relación con el mundo del exilio fue además tardía, como las de Antonio Rodríguez Huéscar y Manuel Granell; la presencia de Ortega en otros autores del exilio, en un sentido más difuso y de forma menos explícita o focalizada en aspectos específicos, como fuera el caso de García Bacca, Ferrater Mora y Francisco Ayala. Obviamente, podrían incorporarse muchos más autores, perfiles y líneas de discusión hasta conformar un legado casi inabarcable, sobre el que sólo queremos llamar la atención señalando sus referencias fundamentales, o por lo menos algunas de ellas.

¿Fue entonces Ortega un filósofo del exilio?

El debate que puede suscitar esta pregunta -y otras en ella implícitas- sigue abierto y a mi modo de ver cabría una respuesta afirmativa aunque muy matizada. La violencia incontrolada que se desató en Madrid como respuesta al golpe militar del 18 de julio motivó, como se sabe, la huida de numerosos intelectuales que, sin manifestarse a favor de dicho golpe, se habían mostrado muy críticos y distantes hacia la República, buscando una difícil si es que no imposible equidistancia, finalmente escorada hacia la derecha en la mayoría de los casos. Tal fue el destino de García Morente, Zubiri, Marañón, Pérez de Ayala, Azorín Baroja y el propio Ortega, entre otros, quienes, pasada la guerra, buscarán acomodo en la España de Franco -lo cual no significa, necesariamente al menos, que lo encontraran. Hubo por tanto un exilio de 1936, tal y como unos cuantos trabajos han venido señalando desde hace ya algún tiempo ${ }^{6}$. En todo caso, la duración de este exilio

6 Lo han planteado, entre otros, Kamen (2007, 273-336) y Giustiniani (2006, 2009). 
previo no se extendió más allá del fin de la guerra, de manera que sus integrantes pudieron regresar inmediatamente después sin temer por la integridad de sus vidas -y dicho sea de paso, sin sufrir el horror de los campos de concentración-, salvo aquellos que, por su clara afinidad anterior a la cultura político-educativa de la República, pasarán a engrosar el exilio del 39 -por ejemplo, Américo Castro, Juan Ramón Jiménez o institucionistas moderados como Luzuriaga.

Es obvio que, en estas coordenadas elementales, la posición de Ortega resulta incómoda, tanto para él mismo como para sus simpatizantes y detractores, y hasta para los estudiosos de su obra. De 1939 a 1942 reside en Buenos Aires, pero permanece distante de la comunidad exiliada y, por lo tanto, también de los círculos intelectuales y académicos argentinos afines a ella. No es que Ortega apoyara al régimen de Franco, pero su silencio al respecto, ligado al que allí mismo mantenía en relación con la Segunda Guerra Mundial, sería inevitablemente interpretado como una señal de conformismo y resignación. Ello le supondría la frialdad de intelectuales y de medios que habían sido muy cercanos a él a raíz de sus viajes anteriores a Argentina como Francisco Romero o el entorno de la revista Sur, y la crítica abierta e incluso ácida del propio Borges, de Guillermo de Torre y del intelectual argentino de origen judío León Dujovne, entre otros. Tampoco es casual que, junto a estas muestras de distancia y rechazo fueran precisamente intelectuales del mundo reaccionario y católico, incluso simpatizantes del nazi-fascismo, quienes procuraran apropiarse de la figura de Ortega, aunque fuera a costa de retorcer su pensamiento o de subrayar, de manera sesgada, su proyección anti-comunista (Medin, 1994: 123-137) ${ }^{7}$.

Estas y otras cuestiones afines se abordan en los tres primeros trabajos del presente monográfico. "El último Ortega y el horizonte del exilio", "Ortega en búsqueda de la circunstancia liberal (1936-1955)" y "Ortega y Gasset en su exilio argentino", a cargo de Eve Fourmont Giustiniani, Juan Bagur Taltavull y Marta Campomar respectivamente, aportan conocimientos y claves hermenéuticas para reflexionar sobre la visión orteguiana de la Guerra Civil, su experiencia como presunto exiliado, su tercer viaje a Argentina y su regreso a la España de Franco.

De lo primero podría destacarse el peso que en dicha visión llegó a desempeñar el anticomunismo, hasta el punto de distorsionar, en buena medida, la realidad misma: Ortega identificaba la República con el comunismo, la acción directa y el mismo peligro de las masas que había diagnosticado algunos atrás en su célebre libro, un reduccionismo que a su juicio justificaba su opción -no sin reservas y como mal menor- por la rebelión franquista, y también su simpatía hacia la política de "appeasement" y de no intervención liderada por su admirado Reino Unido en su versión más conservadora. Aún es más, ello también justificaba, según él, la alarmante alianza provisional entre totalitarismo y liberalismo que había sugerido en su ya mencionado texto "En torno al pacifismo". Todo ello en base a un presunto realismo político que quedará en evidencia tras el comienzo de la Segunda Guerra Mundial, cuando el enemigo común a batir ya no sea el comunismo sino el nazi-fascismo.

7 Para una amplia, rica y matizada contextualización de este episodio en el marco de la presencia española en Argentina durante los años de la Guerra Civil y de la postguerra, desde las gestiones realizadas por la Institución Cultural Española a favor de los exiliados de 1936 hasta el regreso del propio Ortega, pasando por la repercusión de sus obras, gestos y silencios, así como por la interlocución de otros intelectuales desplazados como García Morente, María de Maeztu o el ya mencionado Lorenzo Luzuriaga, véase Campomar (2016). 
Ortega se quedaría así fuera de juego, en una situación tan incómoda que no podía encontrar otra salida que el exilio. Pero un exilio un tanto en falso o demasiado forzado, que de hecho motivará una reflexión sobre el mismo que Eve Fourmont presenta de manera novedosa, apoyándose, en parte, en material inédito. Una reflexión que dispondrá a la razón histórica hacia una razón autobiográfica -algo, por cierto, que su gran discípulo Gaos llevará después hasta sus últimas consecuencias-, y que descubrirá en la vivencia radicalizada de soledad y desarraigo no sólo una fuente insustituible de inspiración para elaborar, por esas mismas fechas, su concepto de ensimismamiento, sino también un síntoma de la violencia propia de los tiempos actuales. Lo primero no era necesariamente negativo, pues esa vivencia de soledad puede comportar también la serenidad necesaria para asumir la soledad ontológica del ser humano y encontrar en la escritura filosófica un nuevo arraigo, exclusivo de minorías egregias y muy a tono con el silencio político que Ortega llevaba años practicando. Lo segundo, la conciencia de la violencia actual, acercaría a Ortega al que será un lugar común en la reflexión del exilio del 39 -no tanto del 36- como es la barbarie consumada bajo las lógicas totalitarias incubadas bajo el manto progresista de la Modernidad. En este caso, el abismo insuperable que a su juicio se abría entre emigrados y autóctonos, incluso siendo unos y otros hablantes de una misma lengua, daba pie a una analogía con el conflicto actual entre los estados y su exacerbación nacionalista, con la consiguiente necesidad de crear un estado supranacional.

Pero no olvidemos que desde 1939 Ortega residía en Buenos Aires, en donde de hecho acababa de publicarse Ensimismamiento y alteración y en donde se acercará a otro lugar común del pensamiento exiliado como es la identidad iberoamericana. Ese será, precisamente, el tema de algunas de sus conferencias en Amigos del Arte, que Marta Campomar comenta en su contribución y que le dan pie a plantear una apertura al conjunto del exilio en Argentina; un exilio muy heterogéneo y no exento de desencuentros, en el que confluyen intelectuales, escritores y científicos tanto del 36 como del 39, sobre el trasfondo de unas relaciones institucionales entre ambos países que habían sido fluidas durante el primer tercio de siglo. La breve y apenas conocida reseña crítica de Carlos Astrada "El centauro y los centauristas. La originalidad del Señor Ortega y Gasset", introducida y comentada por Martín Prestía en el apartado de "Materiales", constituye una muestra del eco que Ortega suscitó durante su tercera y última estancia en Buenos Aires, además de una pequeña aportación documental.

Del regreso de Ortega a España puede decirse algo análogo a su exilio, a saber, que tuvo algo de forzado y de frustrado, como resultado de esa ecuación imposible entre su intimidad y su circunstancia, su ideario supuestamente liberal y su cripto-franquismo anticomunista. Una ecuación cuyos elementos no podían arrojar un resultado del todo coherente ni dentro ni fuera, y que por eso mismo se saldarían con una situación que no dejaba de tener algo de anómalo: residencia en Lisboa desde 1942 y un "semi-regreso" -apunta Bagur recordando una expresión de Juan Pablo Fusi- a España en 1945, en donde Ortega no logrará romper el cerco de la marginalidad académica pese a la afluencia de público en sus intervenciones y en donde su presencia se verá entrecortada por sus viajes a Alemania y a Estado Unidos. ¿Exilio interior? Reservemos este término, de suyo contradictorio y del que tanto se ha abusado, para otros casos, quizá el de su discípulo Antonio Rodríguez Huéscar, al que más adelante nos referiremos. 
Una historia bien diferente fue la de algunos discípulos de Ortega cuya opción por la legalidad y legitimidad republicanas primero, por el exilio después, fue inequívoca. Tales fueron los casos de María Zambrano y de José Gaos, los más conocidos y también, probablemente, los que ofrecen una mayor complejidad en lo que a recepción intelectual se refiere. ${ }^{8}$ Buena prueba de ello es que, tanto en un caso como en el otro, no es en los escritos dedicados de una manera explícita al antiguo maestro, sino en la obra de carácter más personal, en donde puede apreciarse mayormente esa asimilación creativa, aunque a menudo haya que rastrearla entre líneas.

Zambrano es todo un ejemplo de discipulado heterodoxo, el cual se remonta a su temprano y programático ensayo Hacia un saber sobre el alma (1934), en el que radicaliza y al mismo tiempo amplia la noción orteguiana de vida hasta el punto de asimilar todo aquello que el canon occidental había excluido siempre de cualquier definición de razón, a saber, las pasiones, los anhelos, la esperanza, el temor, la intuición, el mundo del sentir y sus lenguajes... Llevaba así a la razón vital más allá de sí misma, por veredas que el maestro había entrevisto sin llegar a recorrerlas, en busca de una razón íntegra o de la "razón de toda la vida del hombre" (Zambrano 2016, 440); de "un saber más amplio" (435) en el que filosofía, poesía y religión no llegan a distinguirse con total nitidez, o un saber, precisamente, sobre el alma entendida como la entraña de la vida; o como dirá a partir de 1937 en plena guerra civil y sobre el trasfondo de una interpretación del fascismo de mayor calado que la de Ortega, "razón poética" (Sánchez Cuervo 2017).

El largo exilio de Zambrano no será sino una búsqueda incesante de ese alma perdida de Occidente, en el que la continuidad entre la "razón vital" y la "razón poética" siempre podrá apreciarse, si bien de una manera cada vez más tenue. La "circunstancia" -apuntará Zambrano en un ensayo de madurez como Los bienaventurados- se transformará entonces en la apariencia de toda una realidad velada y latente, largamente avasallada por las categorías del racionalismo occidental y aprehensible sólo mediante un saber transcendente -o como ella dirá, condescendiente-, más allá de toda razón discursiva e incluso narrativa (Zambrano 2018, 424-425).

El exilio de Zambrano será la búsqueda incesante de esa realidad incógnita y oculta bajo la claridad de la razón vital, recorriendo para ello escenarios bien diversos. Primero el México de la recién fundada Casa de España y de la Universidad Michoacana, en donde residirá el primer año del mismo y en donde publicará dos libros cuya distancia de las tesis orteguianas será ya muy palpable como Pensamiento y poesía en la vida española y Filosofía y poesía -si el primero identificaba lo más genuino de dicho pensamiento con una tradición olvidada y enraizada en el ámbito popular, el segundo daba cuenta, en su mismo título, de cómo y en qué sentido Zambrano estaba reconduciendo la tensión orteguiana entre razón y vida-. Después, durante la década de los cuarenta, en la Cuba de su gran amigo Lezama Lima y el grupo poético Orígenes, y también en la vecina Puerto Rico, uno de los principales focos, por cierto, del orteguismo en el exilio, gracias en parte a la presencia del que fuera rector de la Universidad de Puerto Rico desde 1942, Jaime

8 Lo he planteado en Sánchez Cuervo (2007). 
Benítez. ${ }^{9}$ La propia Zambrano había sido invitada para impartir allí conferencias y cursos de verano, siendo incluso nombrada Catedrática asociada para el curso 1941-42, pero no llegaría a consolidar su puesto debido, seguramente, a la influencia del franquismo en el ámbito académico y cultural de la isla. En todo caso, allí publicaría Isla de Puerto Rico. Nostalgia y esperanza de un mundo mejor (1940), cuyos planteamientos influirán en la Constitución de Puerto Rico como Estado Libre Asociado (Zambrano 2016, 1-51; 581-614) y en donde el simbolismo racio-poético de la insularidad -representación de un logos embrionario o de una realidad auroral aún incipiente- distará ya mucho de las metáforas orteguianas, empezando por la tan célebre del naufragio. Dos figuras, símbolo y metáfora, y dos semánticas que, sin dejar nunca de tocarse, se irán distanciando cada vez más, durante los años romanos de Zambrano, en plena inmersión, ya, en el mundo de los sueños, durante su retiro en La Pièce, en un bosque del Jurá francés, y en su precaria residencia en Ginebra, para regresar a España en 1984, pocos años antes de su muerte y sin renunciar nunca a su condición vital, existencial y simbólica de exiliada. Su exilio logrado, tal y como ella misma lo denominó alguna vez, tocará realidades incomprensibles desde el exilio frustrado de Ortega.

En su contribución "José Ortega y Gasset y María Zambrano: una relación intelectual bidireccional”, Beatriz Caballero Rodríguez identifica los hitos y las claves de esta heterodoxia en torno a conceptos como razón, lenguaje y política, y cuestiones como el alcance de la reforma de aquella o de la crítica de la Modernidad, precisa complicidades y divergencias, y dialoga con algunos intérpretes de referencia. Pero también se pregunta acerca de la tan mentada influencia de Ortega en Zambrano, la cual, sin dejar de ser obvia, cabe relativizar, ponderar e incluso invertir para rastrear el posible sentido bidireccional que en algún momento pudo tener la relación entre ambos intelectuales. Esa es precisamente la nota de originalidad que aporta esta contribución, a propósito sobre todo de las tres cartas que Zambrano dirigió a Ortega a comienzos de los años treinta y de sus presuntos ecos en este último, en medio, siempre, de una relación asimétrica por definición.

Sin llegar a la heterodoxia de Zambrano, Gaos radicalizó con sentido crítico las principales tesis del maestro, señalando además, sin titubeos, su fracaso como filósofo en sentido estricto -es decir, con pretensiones sistemáticas- (Gaos 1999, 231-384). Por otra parte, fue el discípulo del exilio que más escribió sobre el maestro (Gaos, 1992: 43-184; 1999: 177-384; 2013) e incluso elaboró la primera periodización de su obra, a propósito de sus "profecías" (1992, 43-112).

9 Desde su llegada al rectorado de la Universidad en 1942, Benítez proyectó una ambiciosa renovación de la institución como paso previo a posibles reformas posteriores a nivel nacional, encaminadas a un reforzamiento político de la identidad puertorriqueña. Promulgó así una nueva ley que propiciara la apertura a todos los saberes, la internacionalización y la colaboración de profesores extranjeros de prestigio; la ampliación de las facultades y la creación de otras nuevas -entre otras, las de Humanidades y Ciencias Sociales-, el acceso a la enseñanza de todas las clases sociales mediante sistemas de becas, el desarrollo de la investigación y la formación de una ciudadanía comprometida con los valores democráticos y con la cultura puertorriqueña. Para este empeño, el propio Benítez reconocía la influencia intelectual de Ortega y Gasset, especialmente de Misión de la Universidad (1930). El reformismo de la Generación del 14, liderado por Ortega y potenciado por las iniciativas institucionistas de la Junta para la Ampliación de Estudios, había llevado además algunas de sus radiaciones a la isla antes de la Guerra Civil, lo cual favorecería la recepción del exilio republicano del 39. 
Es bien conocida la reformulación que el "transterrado" Gaos planteó del perspectivismo o "circunstancialismo" en clave hispanoamericana, a propósito de su reivindicación de un pensamiento de lengua española y de la proyección transatlántica que imprimió en la noción de "logos del Manzanares", cuestión a la que me he referido en otros lugares (Sánchez Cuervo 2007) y que constituye ya un lugar común. Menos conocida, sin embargo, es su original asimilación de la razón vital. Si en el caso de Zambrano ésta se prolongó de manera heterodoxa hacia una razón poética, Gaos la radicalizó en un sentido autobiográfico, hasta desembocar incluso en un solipsismo, o como él mismo dirá a menudo, en un "inmanentismo", del que darán buena cuenta sus Confesiones profesionales (1958), entre otros escritos. La aportación de Jesús M. Díaz Álvarez, titulada “¿Perdidos en el laberinto? Husserl, Ortega y Gaos ante los desafíos de la diversidad cultural”, tiene que ver con esta cuestión, la cual es abordada desde un ángulo novedoso. En concreto, el de la tensión entre fenomenología e historicismo, certeza y relatividad, la cual recorre buena parte del pensamiento contemporáneo siguiendo, quizá, una cierta progresión desde lo primero hacia lo segundo. O al menos eso es lo que parece sugerir esta comparación entre los tres filósofos, al término de la cual asoma un Gaos poco frecuentado; y no sólo el de la filosofía como autobiografía sin más, sino también el que quiere rescatar las certezas menores que esta última puede ofrecer, liberándolas de esa soberbia inconfesable y por tanto in-comunicativa a la que solía referirse, para contrastarlas con las de otros sujetos y someterlas a un diálogo crítico. "Melancolía serenidad" - en palabras del propio Gaos- frente a soberbia, inmanentismo crítico frente a un relativismo fácil, infecundo y de radio corto.

Tras estas dos referencias inexcusables del legado orteguiano en el exilio, José Lasaga Medina y Noé Expósito Ropero se detienen en dos autores mucho menos conocidos y sin embargo de gran fuste intelectual como Antonio Rodríguez Huéscar y Manuel Granell, respectivamente. Ambos experimentaron, por cierto, el exilio de una manera difusa e incluso algo equívoca, en la línea del común maestro, y no con menos agonía. Incluso mayor en el caso del primero, quien vivió seguramente algo parecido a un "exilio interior" en la España de los cuarenta y los cincuenta; algo parecido a un exilio como tal después, cuando, tras la muerte de Ortega y ante la ausencia de condiciones para desarrollar una vida intelectual y académica digna, decida residir en Puerto Rico; y algo parecido a un regreso cuando, de vuelta en 1972 y hasta su muerte de 1990, no llegue a recibir el reconocimiento merecido.

Republicano, liberal y laico, formado en la última promoción de la Facultad de Filosofía y Letras de la Universidad Central de Madrid en la década anterior a la Guerra Civil, fue un orteguiano ortodoxo que dedicó su obra a esclarecer el pensamiento del maestro, no por gregarismo o servidumbre escolástica, sino por convicción. En este sentido, defendió su condición de filosofía en sentido estricto, a la altura de una metafísica o una filosofía primera, en contra de la opinión habitual no sólo de sus críticos y detractores, sino también de algunos de sus propios discípulos y seguidores, según la cual Ortega sería más bien un ensayista. Por otra parte, defender esa tesis resultaba especialmente comprometido por entonces, pues suponía cuestionar el monopolio del nacional-catolicismo oficial en la confección de una filosofía sistemática en la enseñanza universitaria, así como el proceso de "cristianización" del propio Ortega llevado a cabo por Julián Marías, Pedro Laín, José Luis L. Aranguren o José A. Maravall, entre otros discípulos suyos del interior. 
Rodríguez Huéscar plasmó esa tesis sobre todo en tres libros: Perspectiva y verdad, resultado de su tesis doctoral y publicado en 1966 por la Revista de Occidente; La innovación metafísica de Ortega. Crítica y superación del idealismo (1982) y Ethos y logos, publicado póstumamente en 1966 y resultado de un curso impartido en la Universidad de Puerto Rico en 1967-68, sin olvidar una larga lista de artículos y escritos de la que no es posible dar cuenta ahora. En esta universidad fue docente universitario e impartió varios cursos de clara impronta orteguiana, alguno de ellos sobre la relación entre vida y narración. Pero, para entonces, los tiempos de Benítez y de su reforma universitaria, tan propicia para los profesores e intelectuales del exilio republicano, ya se habían quedado muy atrás y las dificultades para consolidar una nueva vida profesional en la isla motivarían su regreso (véase Lasaga 2011; Díaz Álvarez et al).

"La rebelión contra el tiempo" despliega una cierta panorámica de esta trayectoria a propósito de un ensayo de Rodríguez Huéscar de 1951 sobre el paisaje de su tierra manchega, y de su reflexión, en tono pesimista, sobre el rechazo a la realidad histórica y la peculiar obsesión por la eternidad supuestamente arraigadas en la tradición intelectual y literaria española; algo que habría conducido a la España actual a una nueva "tibetanización”, según el conocido término orteguiano, caracterizada por el desprecio a la vida, el gusto por las glorias del pasado, la "philosophia perennis" y, en definitiva, una "existencia alucinada". Brillante escenificación de todo ello sería el propio Quijote, al que Rodríguez Huéscar dedicó algunas páginas casi desconocidas en las que, curiosamente, se distancia de la interpretación canónica de su maestro, en la medida en que la figura cervantina, al igual que la tradición barroca por ella inaugurada, personificaría el rechazo sistemático de la realidad.

Un perfil hasta cierto punto análogo al de Rodríguez Huéscar, que además nos remite a un ámbito diferente del orteguismo en el exilio como el venezolano, es el de Manuel Granell, quien se auto-exiliará en Caracas en 1950, incorporándose a la Facultad de Filosofía y Letras de la Universidad Central de Venezuela a raíz de una invitación que ésta le había hecho el año anterior. Precisamente en dicha universidad se había publicado en 1958 un Homenaje a Ortega y Gasset, que recogía las ponencias de una sesión académica dedicada al filósofo en diciembre de 1955, con motivo de su muerte. Una de ellas llevaba por título "El sistema de Ortega", en donde Granell resumía una tesis que desarrollaba en algunos de sus libros, en cierto sentido compartida por Rodríguez Huéscar, como era la de la condición sistemática de la filosofía orteguiana, aun cuando se trate de una sistematicidad construida "desde el hecho" o desde "la prioridad cognitiva de lo fáctico", a partir de lo contingente, versátil y observable o, sencillamente, "desde abajo" (AAVV, 1958, 21). La vida como realidad radical sería entonces la "idea placentaria" que articula, cohesiona y dota de "trabazón íntima", no sin tensiones, a esta constelación de elementos primarios. Sería la "infraestructura" o la estructura ontológica en la que se alojarían los dos grandes conceptos de la metafísica tradicional, encontrando una reciprocidad inédita y original: el realismo y el idealismo, los cuales, liberados de sus clásicos reduccionismos, descubren su "mutua inmanencia" en medio de un "doble proceso activista, por el cual ambas partes del todo primigenio van siendo, no son, se forjan en la alteración misma. Es decir, no se realizan con independencia, sino que un aspecto nace del otro." (22) En este sentido, Ortega habría descubierto "un nuevo promontorio metafísico", que hubo de 
explorar largamente antes de llegar a culminación alguna y cuyo proyecto dejó esbozado en su Aurora de la razón histórica. La invitación a realizarlo sería su gran herencia.

Ahora bien, desde otro punto de vista, la interpretación de Granell sería más bien alternativa a la de Rodríguez Huéscar y otros orteguianos como Marías, en el sentido de que rescataría -frente a estos últimos, aunque sin llegar a confrontarse con ellos- la presunta vocación fenomenológica del pensamiento orteguiano. Este es, precisamente, el principal hilo conductor de la contribución de Noé Expósito Ropero "Manuel Granell: filósofo, discípulo y lector de Ortega. El camino fenomenológico de la Estimativa a la Ethología”, en la que se rastrea dicha vocación a partir de la incipiente reflexión de Ortega sobre el mundo de los valores, que su discípulo retomará y desarrollará. Fruto de ello serán sus libros, aún poco explorados, La vecindad humana. Fundamentación de la Ethología (1969), Ethología y existencia (1977) y Humanismo integral (1983), en los que se da cuenta de la relevancia de la ética y de la estética dentro de este marco interpretativo, así como del sentir amoroso y de la vida afectiva en el acceso al mundo del valor. En todo caso, se reaviva el debate hermenéutico en torno a la filosofía de Ortega, cuya pluralidad de opciones siempre será fiel índice de su necesidad.

Ese mismo Homenaje a Ortega y Gasset se abría, por cierto, con el capítulo "Pidiendo un Ortega y Gasset desde dentro" (en obvia alusión al ensayo de este último "Pidiendo un Goethe desde dentro"), firmado por otro de los protagonistas del presente monográfico como Juan David García Bacca, cuyos modos orteguianos son revisados por Alberto Ferrer. Con su contribución, titulada "Los órganos amiboides de Ortega y García Bacca", y las de Carlos Nieto Blanco y Alessio Piras, respectivamente tituladas "Impacto y memoria de Ortega y Gasset en Ferrater Mora" y "Francisco Ayala. Un intelectual orteguiano de vuelta a casa", se completa el monográfico en cuestión, conformando estos tres textos lo que podría ser una cuarta sección dedicada a autores en los que la huella de Ortega fue mucho más difusa que en los anteriores (García Bacca, Ferrater) o en la que se canalizó hacia saberes más específicos, como el sociológico (en un sentido muy amplio) en el caso de Ayala.

En "Pidiendo un Ortega y Gasset desde dentro", García Bacca encontraba la expresión más humana, racional y auténtica de la proyección de todo sujeto en su propia circunstancia en la tarea misma de pensar, entendida como un quehacer, una tarea inagotable y siempre pendiente de completarse -especialmente, afirmaba, en circunstancias como la española... En pleno exilio y en un ambiente de homenaje luctuoso, García Bacca subrayaba la faceta más pedagógica y liberal de Ortega, aquella que le había convertido en supuesto reformador de la nación española, a contrapelo de sus inercias irreflexivas e inquisitoriales, siempre dispuestas a paralizar la iniciativa de la razón crítica. "España es la tierra del miedo a pensar y a dejar que se piense" (AAVV 1958, 11), de las "verdades que se dan por don y gracia" (12), por imperativos de la fe o de la gana más que de la razón, por muy vital que sea, y contra ello se había rebelado Ortega reivindicando la tarea de pensar en términos de "dar razón a la verdad" (13) o de dar sentido al vivir. García Bacca pedía así un Ortega adaptado a la circunstancia del exilio republicano.

García Bacca, uno de los filósofos más singulares e inclasificables, no ya del exilio republicano del 39, sino también de todo el pensamiento español contemporáneo, no era precisamente orteguiano, pero sí estuvo influido por su raciovitalismo y su historicismo de una manera palpable; en concreto en libros como Invitación a filosofar (1940), en los 
que planteaba este último en términos de una tarea vital, en línea con lo que resumiría más tarde en su escrito de homenaje.

Si bien García Bacca pasó la mayor parte de su exilio en Venezuela (en concreto de 1946 a 1971, fijando desde entonces su residencia en Ecuador), había residido previamente en México (1942-1946) para ocupar la cátedra de Metafísica de la Universidad Nacional Autónoma de México. De ese periodo data un curso universitario sobre filosofía contemporánea impartido en 1944 en la Universidad de Nuevo León (Monterrey), que incluye precisamente uno de los comentarios más densos del exilio del 39 dedicados al pensamiento de Ortega, publicado en 1947 en Caracas bajo el título Nueve grandes filósofos contemporáneos y sus temas. Bergson, Husserl, Unamuno, Heidegger, Scheler, Hartmann, W. James, Ortega y Gasset, Whitehead. La presencia de Ortega en este elenco se justificaría por su potente reforma de la razón, o como dice el título del largo capítulo a él dedicado, por el "poder vitamínico" de su filosofía. En este sentido, Ortega sería el máximo artífice de una filosofía de la vida, que García Bacca expone apoyándose en analogías y paralelismos con la ciencia física, que él tan bien conocía desde sus años de formación y en polémica, siempre, con la filosofía especulativa. Frente a la jerarquía ontológica de esta última, que análogamente a la "vulgar física de altura inversa a la densidad" discurre de lo universal a lo particular, lo general a lo especial y lo formal a lo concreto, pulverizando así la realidad mediante análisis y divisiones, Ortega planteará una estratigrafía radicalmente opuesta, inspirada en la razón vital. Un orden inverso, por tanto, en el que las ideas, lejos de definirse en función de su estatuto ontológico, se subordinan a las "vivencias y haciendas interiores", transformándose así en "víveres" (García Bacca 1990, 294) y en cuya cúspide -afirma, citando algunos textos de Ortega de resonancias nietzscheanas- no radica el ser abstracto, sino la vida en su actividad biológica primigenia e irreductible.

De éstas y otras cuestiones se ocupa Alberto Ferrer en su mencionado trabajo, en el que la metáfora de lo amiboide expresa la vocación dinámica y creativa del pensamiento orteguiano, irreductible a cualquier quietismo ontológico o epistemológico. Si pensar es un quehacer, no puede ser algo estático, ni tampoco algo repetitivo o imitador de modelos preestablecidos o ajenos. De ahí la relevancia del estilo, la escritura y la metáfora, que en el caso de Ortega no están reñidos con la exigencia reflexiva e incluso sistemática, lo que le convierte en el gran artífice, o autor al menos, de una filosofía en castellano propiamente dicha.

Una conclusión análoga es la que parece destilar la lectura de "Impacto y memoria de Ortega y Gasset en Ferrater Mora": Ortega, el autor que elevó el castellano a la altura de una lengua filosófica o que supo plantear la pregunta acerca de qué significa pensar en español, entendido siempre como un ejercicio de fidelidad a la realidad temporal, compleja y versátil, como un compromiso de insertar racionalidad en la vida sin domeñarla o reducirla a concepto. Tras una amplia y completa semblanza del pensador catalán, Carlos Nieto recorre, de manera muy documentada, los diversos escritos que Ferrater dedicó a un maestro del que nunca fue discípulo, pero de cuya influencia nunca escapó. Así lo muestran su brevísima pero significativa correspondencia con el propio Ortega en 1936, en la prehistoria del que será su célebre Diccionario de filosofía; un buen número de artículos y referencias contenidas en libros, desde el temprano Cóctel de verdad (1935) hasta artículos periodísticos de los años ochenta, pasando por colaboraciones en revistas emblemáticas del exilio como La Torre o del interior como Ínsula, y por supuesto, Ortega y Gasset, an outline of his philosophy (Yale University 
Press, 1957), primer libro sobre Ortega en inglés y uno de los primeros en cualquier otra lengua, varias veces reeditado tanto en versión original como en su traducción al español. Ofrecía una visión evolutiva y narrativa del pensamiento de Ortega, dividido en tres etapas (objetivismo, perspectivismo y raciovitalismo), y salía al paso de la manida objeción según la cual Ortega es un ensayista o un pensador versátil, de circunstancias, sin llegar nunca a formular una filosofía verdaderamente sistemática pese a su empeño en ello. La postura de Ferrater en contra de este tópico puede recordar la de otros orteguianos antes mencionados, pero su respuesta es al mismo tiempo más flexible y menos comprometida de lo que podrían serlo las de Rodríguez Huéscar o Granell. Siguiendo sus planteamientos, quizá podría resultar excesivo hablar de un sistema en Ortega, pero no de un método riguroso, de carácter narrativo o biográfico, inspirado en la estructura peculiar de la vida humana y sus realizaciones históricas. El libro en cuestión daba buena cuenta, por lo demás, de la presencia de Ortega en el pensamiento de Ferrater, incluso tras su "giro lingüístico" una vez instalado en el Bryan Mawr College de Pennsylvannia, a partir de 1947. Si durante su exilio en Chile (1941-1947) dicha presencia podría resultar casi obvia por los temas que allí cultivó, no pocos de ellos ligados a la tradición cultural española (por ejemplo, el encaje entre España y Europa en medio de un mundo convulso, en el que nunca dejó de incorporar a Catalunya con una voz propia bajo la tesis del federalismo), durante su residencia en Estados Unidos nunca llegará a desaparecer, tal y como se documenta en este trabajo.

Una visión de Ortega como el pensador cuyo legado siempre debe actualizarse puede encontrarse también en la obra de Francisco Ayala, cuestión a la que Alessio Piras dedica el último artículo de este número monográfico. "Francisco Ayala. Un intelectual orteguiano de vuelta a casa" se centra en el que probablemente sea uno de los aspectos más relevantes de dicho legado, como es el papel del intelectual, cuya actualización desde la publicación de La rebelión de las masas hasta los años de la transición en España, que Ayala quiso vivir con un protagonismo responsable, pasa por un equilibrio entre el pasado como referencia (el proyecto cívico de la República) y el futuro como oportunidad (el nuevo estado demoliberal surgido de la transición).

La referencia de Ayala a La rebelión de las masas no es gratuita ni era, ni mucho menos, nueva. Tal y como recordara en su día Tzvi Medin (1994, 158-161), en su Introducción a las ciencias sociales, resultante de un curso impartido en la Universidad de Puerto Rico en 1951, se planteaba una meditación sobre la crisis actual en clave sociológica, a propósito de la formación de la sociedad de masas. En el capítulo X, dedicado a la "formación de la sociedad de masas", Ayala hacía de hecho un elogio explícito de La rebelión de las masas (Ayala 1952, 264-265), advirtiendo al mismo tiempo su inevitable desfase veinticinco años después, con acontecimientos tan traumáticos de por medio como la experiencia totalitaria, la Segunda Guerra Mundial y el nuevo capitalismo de masas. En este sentido, rectificaba algunos aspectos de la tesis central del libro, aunque valiéndose de los propios enfoques orteguianos o llevándolos a la práctica de manera consecuente. Ayala no fue un heterodoxo como Zambrano, pero sí proyectaría esos enfoques en un ámbito específico como el sociológico, que desarrollará de manera compleja y bajo su propia impronta. ${ }^{10}$

10 En relación con la tesis orteguiana del hombre-masa, objetará su supuesta intemporalidad, al margen de las circunstancias históricas que la han gestado y que se remontarían a la revolución industrial y a las revolucio- 
Volviendo, para concluir, al artículo de Alessio Piras, el horizonte de la transición, que Ayala ya preveía en los años sesenta en libros como España, a la fecha, era sin duda muy diferente y también muy exigente, en pleno ocaso de las grandes ideologías y en un medio ampliamente despolitizado. Ayala se hará entonces orteguianamente presente en revistas, periódicos y otros espacios de la plaza pública, defendiendo las bondades de la democracia liberal y de un europeísmo superador de viejos nacionalismos.

Es obvio que este recorrido ni es exhaustivo ni pretende serlo. Muy ingenuos habríamos de ser quienes hemos contribuido a su trazado si así lo creyéramos. Son abundantes los problemas, aspectos y obras que se abordan sobre la relación de Ortega y de su legado con el exilio, pero a costa, obviamente, de dejar otros a un lado o de apenas mencionarlos. De manera igualmente obvia, los autores seleccionados no son los únicos que podrían incluirse en un monográfico con este perfil y unos cuantos más deberán estar presentes en eventuales aproximaciones futuras, más ambiciosas, a esta temática. Y no sólo por haber adoptado modos de pensar orteguianos, sino también por haberlos contrastado con otros planteamientos, por haberlos considerado de alguna manera e incluso por haberlos refutado o sometido a crítica. En el caso del exilio en México, por ejemplo, quedaría pendiente abordar la influencia de Ortega en un campo específico como el de la filosofía del derecho, que tan ampliamente desarrolló Luis Recasens Síches; o en discípulos de Gaos como Fernando Salmerón, quien dedicará su tesis doctoral a las mocedades de Ortega (Salmerón 1959), o el propio Leopoldo Zea, como advirtiera, también en su día, Tzvi Medin (1998). También debería tenerse en cuenta una recepción difusa u oblicua como la que puede apreciarse en Personas y masas. En torno al problema de nuestro tiempo, un libro publicado en 1944 por el sacerdote republicano José M. Gallegos Rocafull, de indudables resonancias orteguianas y no por casualidad, pues está dedicado al análisis del hombre-masa, base y esencia, a su juicio, de los regímenes totalitarios que han llevado a Europa a la catástrofe, especialmente el nazismo. Sigue las pautas de La rebelión de las masas -de hecho lo cita de manera explícita en alguna ocasión (1944, 24, 48)- a la hora de describir esta figura tan actual, aunque con un sesgo propio y desde la perspectiva, más cruda y realista, de la guerra y la violencia totalitaria consumadas; pero sin el menor empeño en "cristianizar" o sencillamente condenar a Ortega, como sucediera por esos mismos años en la España del interior, y dialogando con él con un sentido crítico. Este mismo sentido, más radicalizado, es el que llevaría a Eduardo Nicol a cuestionar profundamente a Ortega -y a su contemporáneo Gaos- desde la experiencia de la alteridad, la

nes burguesas del siglo XVIII. Es decir, se trataría de una figura o una mentalidad estrechamente ligada al desarrollo del capitalismo e incluso propiciada y hasta necesitada por él, cuyo protagonismo actual vendría a culminar un proceso en cierto sentido negativo. A juicio de Ayala, los principios igualitarios y demo-liberales enarbolados por las revoluciones burguesas habrían ido derivando, bajo la presión de la lógica capitalista, hacia una especie irreflexiva de uniformidad y un colectivismo irracional que, habiendo alcanzado su zenit bajo los regímenes totalitarios, seguiría vigente en la actual industria cultural y de consumo, e incluso aupada por ella. El declive del individualismo burgués y el acceso a cierto bienestar por parte del proletariado habría propiciado la conformación del hombre-masa, favorecida además por otros factores tales como el crecimiento demográfico, el desarrollo de grandes núcleos urbanos o la implementación de la propaganda y otras técnicas de manipulación psico-social y emocional, con fines no sólo comerciales sino también políticos. El hombremasa sería por tanto la expresión de un gran "vacío vital" (309), dirá Ayala empleando un término de claras resonancias orteguianas. 
comunidad y la intersubjetividad, en base a las que construyó su "metafísica de la expresión" y su "razón simbólica". Una crítica como la de Nicol también debería figurar en un recorrido exhaustivo por los legados de Ortega en el exilio. Y también, por supuesto, otros horizontes distintos del mexicano, como el chileno, en el que se ubicaría Francisco Soler Grima, orteguiano de una generación más joven que la de Rodríguez Huéscar o Marías, con quien había colaborado en el Instituto de Humanidades fundado por Ortega tras su regreso a España, principal exponente del orteguismo en Chile tras la marcha de Ferrater a Estados Unidos, además de traductor de Heidegger y autor de Hacia Ortega I. El mito del origen del hombre (1965). O también otros perfiles no estrictamente filosóficos, como el de Rosa Chacel, entre otros. Se trata sólo de algunas sugerencias con la intención de incitar a la exploración de un legado laberíntico y casi imposible de delimitar, así como a la discusión de sus contenidos, posibilidades, limitaciones, huecos y aportaciones.

Para concluir, sólo me resta agradecer a Daimon - Revista internacional de filosofía, su amable disposición y generosidad para publicar este suplemento.

\section{Bibliografía citada}

AAVV (1958), Homenaje a Ortega y Gasset, caracas: Universidad Central de Venezuela.

Ayala, F. (1949), "Para quién escribimos nosotros", en Cuadernos americanos, 43, 197-223. Ayala, F. (1952), Introducción a las ciencias sociales. Madrid: Aguilar.

Campomar, M. (2016), Ortega y Gasset. Luces y sombras del exilio argentino. Madrid: Biblioteca Nueva.

Cortés, F. J. (2017), "Congreso internacional El legado de Ortega y Gasset en el exilio republicano de 1939: continuidades y rupturas", en Revista de hispanismo filosófico, $22,352 \mathrm{~s}$.

Díaz Álvarez, J.M., Lasaga Medina, J., Esteban Enguita, J.E. (eds.) (2015), Antonio Rodríguez Huéscar: una vocación filosófica, en Bajo palabra. Revista de filosofía, 11.

Gallegos Rocafull, J.M. (1944) Personas y masas. En torno al problema de nuestro tiempo. México: Ediciones del Valle.

Gaos, J. (1992), Obras completas IX. Sobre Ortega y Gasset y otros trabajos de historia de las ideas en España y la América española, prólogo de Octavio Castro. México: UNAM.

Gaos, J. (1999), Obras completas X. De Husserl, Heidegger y Ortega, prólogo de Laura Mues de Schrenk. México: UNAM.

García Bacca, J.D. (1990), Nueve grandes filósofos contemporáneos y sus temas. Bergson, Husserl, Unamun o, Heidegger, Scheler, Hartmann, W.James, Ortega y Gasset, Whitehead. Madrid: Anthropos.

Giustiniani,E.(2006), “Ortega y Gasset pendant la guerre d'Espagne(1936-1939): l'ambiGüité au service de la continuité", en Bulletin d'hitoire contemporaine de l'Espagne, 301-325.

Giustiniani, E. (2009), "El exilio de 1936 y la Tercera España. Ortega y Gasset y los blancos de París. Entre franquismo y liberalismo". En Circunstancia, 19.

Kamen, H. (2007), Los desheredados. España y la huella del exilio, Madrid: Aguilar

Lasaga, J. (2011), “Antonio Rodríguez Huéscar: el momento ‘escolar' de la filosofía”. Boletín de estudios de filosofía y cultura Manuel Mindán VI107-128.

Medin, T. (1994), Ortega y Gasset en la cultura hispanoamericana. México: FCE. 
Medin, T. (1998), Entre la jerarquía y la liberación. Ortega y Gasset y Leopoldo Zea, México: FCE-UNAM.

Ortega y Gasset, J. (2013), La rebelión de las masas. Edición de Domingo Hernández Sánchez tercera edición corregida y aumentada, Madrid: Tecnos.

Sánchez Cuervo, A. (2007), "El pensamiento de Ortega y Gasset bajo dos miradas del exilio: salvación y superación", en Solar 3, 41-54.

Sánchez Cuervo, A. (2017), "Dos interpretaciones del fascismo: Ortega y Gasset y maría Zambrano", en Bajo palabra. Revista de filosofía, 13 (2017), 61-75.

Zambrano, M. (2016), Obras completas II. Libros (1940-1950), edición dirigida por Jesús Moreno Sanz. Barcelona: Galaxia Gutenberg.

Zambrano, M. (2018), Obras completas IV-2. Libros (1977-1990), edición dirigida por Jesús Moreno Sanz. Barcelona: Galaxia Gutenberg. 
